\title{
DRYING CHARACTERISTICS IN A PACKED FLUIDIZED BED DRYER
}

\author{
Kunio KATO, Shinji OHMURA, Daisuke TANEDA, \\ ICHIRO ONOZAWA, KAZUHIRO SHIMURA \\ AND AKIRA IIJIMA \\ Department of Chemical Engineering, \\ Gunma University, Kiryu 376
}

\begin{abstract}
Wet particles of activated alumina were dried in batch and continuous packed fluidized beds with open-end cylindrical screen packings. The drying characteristics of the packed fluidized bed dryers was investigated.

The drying rate in the constant drying rate period can be estimated by the empirical equation for gas-particle heat transfer coefficient obtained by Kato et $a l^{1)}$, and the drying rate in the falling drying rate period is proportional to the free moisture content in the particles. Both overall drying rate in the continuous packed fluidized bed dryer and outlet gas temperature from the bed were affected by superficial gas velocity, bed height, inlet gas temperature, average residence time of particles in the bed and packing size.

The drying characteristics of a continuous packed fluidized bed dryer is analyzed by the plug flow model for the gas flow pattern and the plug flow model or the perfect mixing model for the particle flow pattern in the bed.

If the packing size is smaller than $2.5 \mathrm{~cm}$, and the average residence time of particles is less than 30 minutes, the drying characteristics in the bed can be analyzed by the plug flow model for the particle flow pattern in the bed and the plug flow model for the gas flow pattern.
\end{abstract}

\section{Introduction}

A fluidized bed dryer is one of the practical applications of the fluidized bed principle. The fluidized bed dryer has the following advantages: the structure of equipment is simple, and there are no moving parts in the dryer. Since the heat capacity coefficient between gas and particles is very large, particles are dried efficiently. Control of particle residence time in the bed is easy. However, the fluidized bed dryer has the following disadvantages: since the particle flow pattern in the bed is one of almost perfect mixing, the moisture content of outlet particles is not uniform. As the gas bubbles grow in the bed, the contact of particles with gas is not uniform throughout the bed. In the packed fluidized bed, the packings prevent the growth of gas bubbles and also control the mixing of particles in the bed.

Toei et $a l^{31}$ and Mrowiec and Ciesielczyk ${ }^{2)}$ investigated the drying characteristics of various fluidized bed dryers. Toei et al.$^{4,5)}$ showed that the drying rate in the falling drying rate period was proportional to the free moisture content in the particles when particles were uniformly dispersed in the dryer. Moreover, Toei et al. ${ }^{4,5)}$ proposed process design methods for

Received December 12, 1981. Correspondence concerning this article should be addressed to K. Kato. S. Ohmura is now with Dainippon Ink \& Chemicals, Inc. the shallow multisectional fluidized bed and the countercurrent multistage fluidized bed.

In this study, wet particles of activated alumina were dried in batch and continuous packed fluidized beds with open-end cylindrical screen packings. In the batch operation, the drying rate in the constant drying rate period and the relationship between drying rate and free moisture content were investigated. In the continuous operation, both the moisture content of outlet particles of activated alumina and the temperature of outlet gas were measured at the various average residence times of particles in the bed. The effects of superficial gas velocity, bed height, particle diameter, packing size and inlet gas temperature upon the drying characteristics were investigated. The drying characteristics of a continuous packed fluidized bed dryer were analyzed by the plug flow model for the gas flow pattern and the plug flow model or the perfect mixing model for the particle flow pattern in the bed.

\section{Experimental Apparatus and Procedure}

A schematic diagram of the experimental apparatus is shown in Fig. 1. The main part of the apparatus consisted of a rectangular column made of stainless steel, $30 \mathrm{~cm}$ wide, $10 \mathrm{~cm}$ long and $50 \mathrm{~cm}$ high.

Air from the compressor was passed through dehydration towers filled with silica gel, and was heated to a constant temperature by the electric heater before 


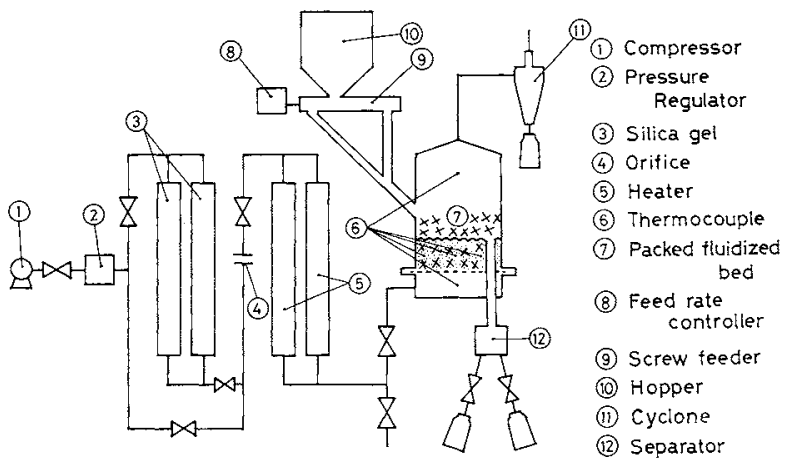

Fig. 1 Experimental apparatus

Table 1 Properties of activated alumina

\begin{tabular}{cccc}
$\begin{array}{c}D_{p} \\
{[\mathrm{~cm}]}\end{array}$ & $\begin{array}{c}U_{m f} \\
{[\mathrm{~cm} / \mathrm{sec}]}\end{array}$ & $\begin{array}{c}\phi_{s} \\
{[-]}\end{array}$ & $\begin{array}{c}\varepsilon_{m f} \\
{[-]}\end{array}$ \\
\hline 0.0342 & 2.3 & & \\
0.0418 & 4.2 & 1.0 & 0.45 \\
0.0500 & 7.2 & & \\
\hline
\end{tabular}

Table 2 Screen packing used in experiment

\begin{tabular}{lccccc} 
Sign & $\begin{array}{c}\text { Taylor } \\
\text { mesh }\end{array}$ & $\begin{array}{c}d \\
{[\mathrm{~cm}]}\end{array}$ & $\begin{array}{c}h_{c} \\
{[\mathrm{~cm}]}\end{array}$ & $\begin{array}{c}D_{p}{ }^{*} \\
{[\mathrm{~cm}]}\end{array}$ & $\begin{array}{c}\varepsilon_{b} \\
{[-]}\end{array}$ \\
\hline PN-3 & 10 & 1.43 & 1.30 & 1.59 & 0.967 \\
PN-4 & 32 & 1.22 & 1.20 & 1.39 & 0.975 \\
PN-7 & - & 2.73 & 4.22 & 3.61 & 0.990 \\
PN-9 & 6 & 2.00 & 2.54 & 2.48 & 0.990 \\
PN-10 & 16 & 2.00 & 2.54 & 2.48 & 0.990 \\
\hline
\end{tabular}

entering the packed fluidized bed. The flow rate of air was measured by the orifice meter. The column, the heating towers and the tube between the column and the heating towers were covered with glass wool as heat insulator to minimize heat loss. The particles and the packings used for this experiment are shown in Tables 1 and 2, respectively.

The experimental procedure was as follows. After the inlet gas temperature became constant, particles with constant moisture content were fed to the bed at constant rate by the feeder and were fluidized by hot, dry air at a constant flow rate. The dried particles were continuously discharged from the bed by the downcomer. After the bed reached steady state, sample particles were taken from the particles exit at constant time intervals, and the particle feed rate and moisture content of outlet particles were measured. The electric potential differences of the thermocouples in the bed were continuously recorded.

\section{Computation Method}

To analyze the drying characteristics of a continuous packed fluidized bed dryer, the following two cases are considered.

Case A: The plug flow model for the particle flow pattern and the plug flow model for the gas flow pattern in the bed.

Case B: The perfect mixing model for the particle flow pattern and the plug flow model for the gas flow pattern in the bed.

\section{1 Calculation method in Case A:}

The following assumptions are made.

1. The drying rate in the falling drying rate period is proportional to the free moisture content in the particles.

2. The evaporation of water from fluidized particles in the preheating period may be negligible.

3. Both the critical moisture content and the equilibrium moisture content are known.

To estimate the gas-particle heat transfer coefficient in a packed fluidized bed, the following empirical equation obtained by Kato et al. ${ }^{11}$ is used:

$$
N u=h D_{p} / K_{g}=0.59 \operatorname{Rep}^{1.1}\left(D_{p} / L_{f}\right)^{0.9}
$$

1) Preheating period In the preheating period, the following equation is obtained by the heat balance in the small increment $d x$ in the lateral direction.

$$
W\left(C_{p s}+C_{p w} w_{F}\right) \frac{d t_{m}}{d x} \cong \frac{G C_{p g}\left(T_{1}-T_{2}\right) L_{H}}{A}-2 h_{l} L_{f} \Delta T_{l n}
$$

where $\quad \Delta T_{l_{n}}=\frac{\left(T_{1}-t_{F}\right)-\left(T_{2}-t_{F}\right)}{\ln \left\{\left(T_{1}-t_{F}\right) /\left(T_{2}-t_{F}\right)\right\}}$

The boundary condition: $t_{m}=t_{F}$ at $x=0$

From gas-particle heat transfer in the small increment $d Z$, the following equation is obtained.

$$
\frac{G C_{p g} L_{H}}{A} \frac{d T}{d Z}=h a L_{H}\left(T-t_{m}\right)+2 h_{l}\left(T-t_{F}\right)
$$

The boundary conditions: $T=T_{1}$ at $Z=0$

$$
T=T_{2} \text { at } Z=L_{f}
$$

Integrating Eq. (3) gives

$$
\frac{T_{2}-\frac{h a L_{H} t_{m}+2 h_{l} t_{F}}{h a L_{H I}+2 h_{l}}}{T_{1}-\frac{h a L_{H} t_{m}+2 h_{l} t_{F}}{h a L_{H}+2 h_{l}}}=\exp \left\{-\frac{\left(h a L_{H}+2 h_{l}\right) V}{G C_{p g} L_{H}}\right\}
$$

The temperatures of particles and outlet gas can be calculated from Eqs. (2) and (4) as a function of lateral distance $x$. The calculation is continued until the temperature of particles reaches the wet-bulb temperature of the inlet gas.

2) Constant drying rate period For the constant drying rate period, the following equation is obtained.

$$
\begin{aligned}
W r_{w}\left(w_{F}-w\right)= & \frac{G C_{H} L_{H}\left(T_{1}-T_{2}\right)}{A}\left(x-x_{p}\right) \\
& -2 h_{l} L_{f} \Delta T_{l n}\left(x-x_{p}\right)
\end{aligned}
$$

From gas-particle heat transfer,

$$
\frac{T_{2}-\frac{h a L_{H} t_{w}+2 h_{l} t_{F}}{h a L_{H}+2 h_{l}}}{T_{1}-\frac{h a L_{H} t_{w}+2 h_{l} t_{F}}{h a L_{H}+2 h_{l}}}=\exp \left\{-\frac{\left(h a L_{H}+2 h_{l}\right) V}{G C_{H} L_{H}}\right\}
$$

The moisture content of particles and the temperature of outlet gas can be calculated from Eqs. (5) and 
(6) as a function of lateral distance $x$. The calculation is continued until the moisture content of the particles reaches the critical moisture content $w_{c}$.

3) Falling drying rate period The drying rate in the constant drying rate period is expressed as

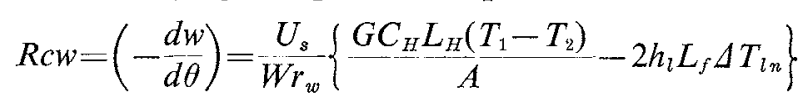

where

$$
U_{s}=\frac{W}{L_{H} L_{f}\left(1-\varepsilon_{f}\right) \rho_{0}}
$$

From assumption 1, the equation for the drying rate in the falling drying rate period is obtained as

$$
R d w=\left(-\frac{d w}{d \theta}\right)=R c w\left(\frac{w-w_{e}}{w_{c}-w_{e}}\right)
$$

Integrating Eq. (8) gives

$$
\frac{w-w_{e}}{w_{c}-w_{e}}=\exp \left\{-\frac{R c w\left(x-x_{e}\right)}{U_{s}\left(w_{c}-w_{e}\right)}\right\}
$$

The following equation is obtained by the heat balance in the small increment $d x$.

$$
\begin{aligned}
W\left(C_{p s}+C_{p w} w\right) \frac{d t_{m}}{d x}= & \frac{G C_{H} L_{H}\left(T_{1}-T_{2}\right)}{A}-r_{m} W \frac{R c w}{U_{s}} \\
& \times\left(\frac{w-w_{e}}{w_{c}-w_{e}}\right)-2 h_{l} L_{f} \Delta T_{l \eta}
\end{aligned}
$$

The boundary condition: $t_{m}=t_{w}$ at $x=x_{c}$

From gas-particle heat transfer, the following equation is obtained.

$$
\begin{aligned}
& T_{2}-\frac{h a L_{I I} t_{m}+2 h_{l} t_{F}}{h a L_{H}+2 h_{l}} \\
& T_{1}-\frac{h a L_{H} t_{m}+2 h_{l} t_{F}}{h a L_{H}+2 h_{l}}
\end{aligned}=\exp \left\{-\frac{\left(h a L_{H}+2 h_{l}\right) V}{G C_{H} L_{H}}\right\}
$$

The temperatures of particles and outlet gas and the moisture content of particles can be calculated from Eqs. (9), (10) and (11) as a function of lateral distance $x$.

\section{2 Calculation method in Case B:}

Particles flow through the bed in perfect mixing. The other assumptions are the same as those in the case of the plug flow model for the particle flow pattern in the bed.

A material balance of water across the bed gives

$$
G\left(H_{2}-H_{1}\right)=W\left(w_{F}-\bar{w}_{\text {out }}\right)
$$

Also, a heat balance across the bed gives

$$
\begin{aligned}
& G\left(C_{p g}+C_{w} H_{1}\right) T_{1}-G\left(C_{p g}+C_{w} H_{2}\right) T_{2}-h_{l} A_{l} \Delta T_{l n} \\
&= W\left(C_{p s}+C_{p w} \bar{w}_{\text {out }}\right) \bar{t}_{m 2}+W r_{m}\left(w_{F}-\bar{w}_{\text {out }}\right) \\
&-W\left(C_{p s}+C_{p w} w_{F}\right) t_{F}
\end{aligned}
$$

where

$$
\Delta T_{l_{n}}=\frac{\left(T_{1}-t_{F}\right)-\left(T_{2}-t_{F}\right)}{\ln \left\{\left(T_{1}-t_{F}\right) /\left(T_{2}-t_{F}\right)\right\}}
$$

From gas-particle heat transfer in the bed, the following equation is obtained.

$$
\frac{T_{2}-\frac{h a A \bar{t}_{m 2}+h_{l} L t_{F}}{h a A+h_{l} L}}{T_{1}-\frac{h a A \bar{t}_{m 2}+h_{l} L t_{F}}{h a A+h_{l} L}}=\exp \left(-\frac{h a V+h_{l} A_{l}}{G C_{H}}\right)
$$

Let us consider the drying rate of a single wet particle in a packed fluidized bed for the following three cases. 1) Preheating period In the preheating period, the following equation is obtained by the heat balance in a particle.

$$
W_{p}\left(C_{p s}+C_{p w} w_{F}\right) \frac{d t_{m}}{d \theta}=h S_{p}\left(\bar{T}_{g}-t_{m}\right)
$$

where $\bar{T}_{g}$ is mean gas temperature in the bed.

The initial condition: $t_{m}=t_{F}$ at $\theta=0$

The time when the temperature of a particle reaches the wet-bulb temperature of the inlet gas is

$$
\theta_{p}=\frac{W_{p}\left(C_{p s}+C_{p w} w_{F}\right)}{h S_{p}} \ln \left(\frac{\bar{T}_{g}-t_{F}}{-\overline{\bar{T}}_{g}-t_{w}}\right)
$$

2) Constant drying rate period The drying rate in the constant drying rate period is

$$
R c w=\left(-\frac{d w}{d \theta}\right)=\frac{h S_{p}\left(\bar{T}_{g}-t_{w}\right)}{r_{w} W_{p}}
$$

The time when the moisture content of a particle reaches the critical moisture content is

$$
\theta_{0}=\frac{\left(w_{F}-w_{c}\right)}{R c w}+\theta_{p}
$$

3) Falling drying rate period From assumption 1, the following equation is obtained.

$$
\frac{w-w_{e}}{w_{c}-w_{e}}=\exp \left\{-\frac{\operatorname{Rcw}\left(\theta-\theta_{c}\right)}{\left(w_{c}-w_{e}\right)}\right\}
$$

From the heat balance in a particle:

$$
\begin{aligned}
& W_{p}\left(C_{p s}+C_{p w} w\right) \frac{d t_{m}}{d \theta}+r_{m} W_{p} R c w\left(\frac{w-w_{e}}{w_{c}-w_{e}}\right) \\
& =h S_{p}\left(\bar{T}_{g}-t_{m}\right)
\end{aligned}
$$

The initial condition: $t_{m}=t_{w}$ at $\theta=\theta_{c}$

The average moisture content and average temperature of outlet particles are obtained as follows:

$$
\begin{aligned}
\bar{w}_{\text {out }}= & \int_{0}^{\infty} w J^{\prime}(\theta) d \theta \\
= & w_{F} \int_{0}^{\theta_{p}} J^{\prime}(\theta) d \theta+\int_{\theta_{p}}^{\theta_{c}}\left\{w_{F}-R c w\left(\theta-\theta_{p}\right)\right\} J^{\prime}(\theta) d \theta \\
& +\int_{\theta_{c}}^{\infty}\left[\left(w_{c}-w_{e}\right) \exp \left\{-\frac{R c w\left(\theta-\theta_{c}\right)}{\left(w_{c}-w_{e}\right)}\right\}+w_{e}\right] \\
& \times J^{\prime}(\theta) d \theta \\
\bar{t}_{m 2}= & \int_{0}^{\infty} t_{m} J^{\prime}(\theta) d \theta \\
= & \int_{0}^{\theta_{p}}\left[\bar{T}_{g}-\left(\bar{T}_{g}-t_{F}\right) \exp \left\{-\frac{h S_{p} \theta}{W_{p}\left(C_{p s}+C_{p w} w_{F}\right)}\right\}\right] \\
& \times J^{\prime}(\theta) d \theta+t_{w} \int_{\theta_{p}}^{\theta_{c}} J^{\prime}(\theta) d \theta+\int_{\theta_{c}}^{\infty} t_{m} J^{\prime}(\theta) d \theta
\end{aligned}
$$

where 


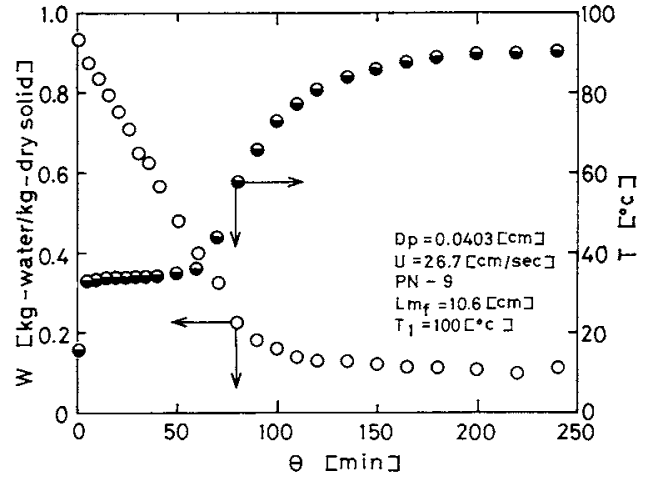

Fig. 2 Relationship between $W, T$ and $\theta$

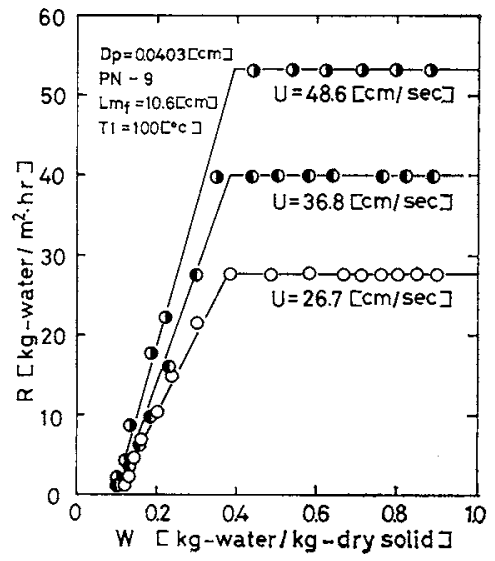

Fig. 3 Relationship between $R$ and $W$

$$
\vec{\theta}_{T}=\frac{L_{H} L_{f} X_{T}\left(1-\varepsilon_{f}\right) \rho_{0}}{W}, \quad J^{\prime}(\theta)=\frac{1}{\bar{\theta}_{T}} \exp \left(-\frac{\theta}{\bar{\theta}_{T}}\right)
$$

The calculation procedure is as follows.

$\bar{T}_{g}$ is assumed. $\theta_{p}$ and $\theta_{c}$ are calculated from Eqs. (16) and (18). $\quad \bar{w}_{\text {out }}$ and $\vec{t}_{m 2}$ are calculated from Eqs. (21) and (22). $H_{2}$ and $T_{2}$ are calculated from Eqs. (12) and (14). These calculations are continued until the right side of Eq. (13) is equal to the left side of Eq. (13).

\section{Experimental Results and Comparison of Exper- imental and Calculated Results}

\section{1 Batch operation}

Before investigating the drying characteristics of particles in the continuous packed fluidized bed dryer, the particles were dried in the batch packed fluidized bed. Figure 2 shows the relationship between moisture content of fluidized particles, outlet gas temperature and residence time of particles in the bed. Figure 3 shows the relationship between drying rate and moisture content of particles, with superficial gas velocity as a parameter. From Fig. 3, when the superficial gas velocity is large, the drying rate in the constant drying rate period and the critical moisture content become large. The constant drying rate was also affected by bed height and inlet gas temperature.

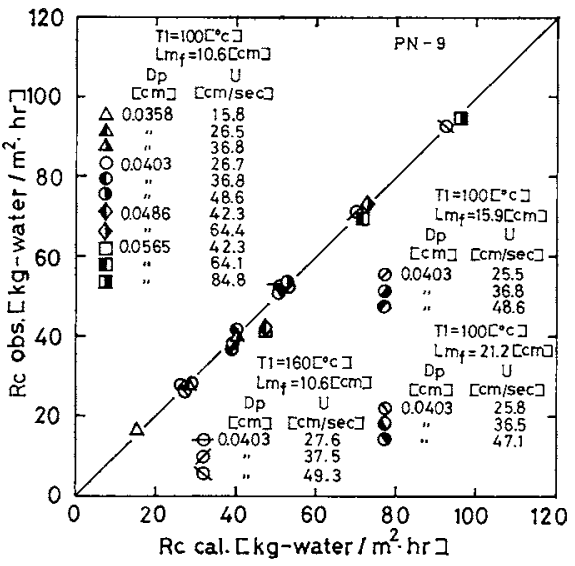

Fig. 4 Comparison of calculated and observed constant drying rates

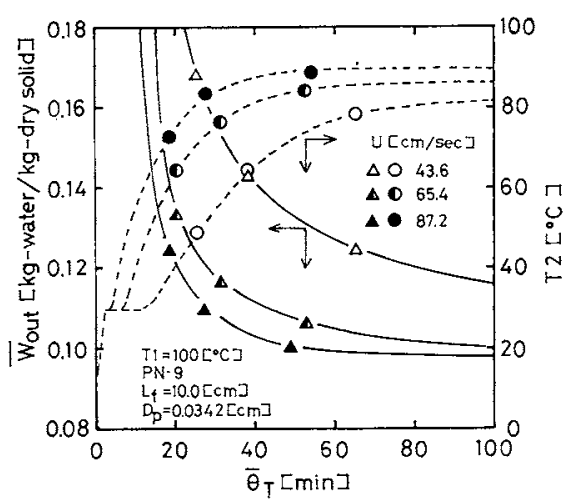

Fig. 5 Effect of $U$ upon $\bar{w}_{\text {out }}, T 2$

From Fig. 3, $R$ decreases linearly with $\left(w-w_{e}\right)$ in the falling drying rate period.

Since the drying rate in the constant drying rate period is controlled by the gas-particle heat transfer rate, it can be calculated by the gas-particle heat transfer coefficient. Figure 4 compares the calculated drying rate in the constant drying rate period by the empirical equation for gas-particle heat transfer coefficient obtained by Kato et al. ${ }^{1)}$ with the experimental rates. From Fig. 4, the calculated values agree well with the experimental ones. Therefore, it is possible to estimate the drying rate in the constant drying rate period by the empirical equation for gasparticle heat transfer coefficient obtained by Kato et al. ${ }^{11}$.

\section{2 Continuous operation}

When wet particles were dried in a continuous packed fluidized bed dryer, the factors affecting the drying characteristics of particles were superficial gas velocity, particle diameter, bed height, inlet gas temperature, packing size and average residence time of particles in the bed.

Figure 5 shows the relationship between moisture content of outlet particles, outlet gas temperature and average residence time of particles in the bed, with superficial gas velocity as a parameter. From Fig. 5, 


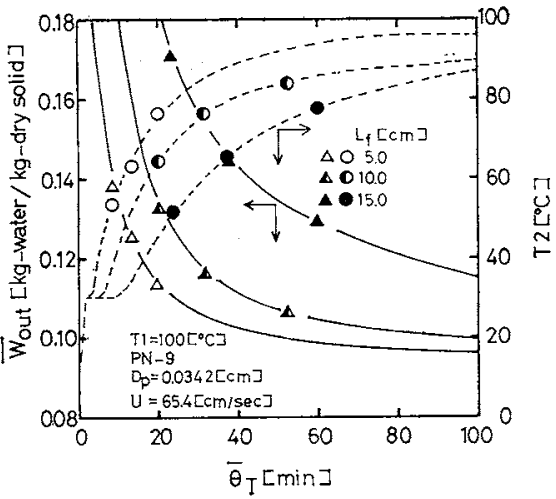

Fig. 6 Effect of $L_{f}$ upon $\bar{w}_{\text {out }}, T 2$

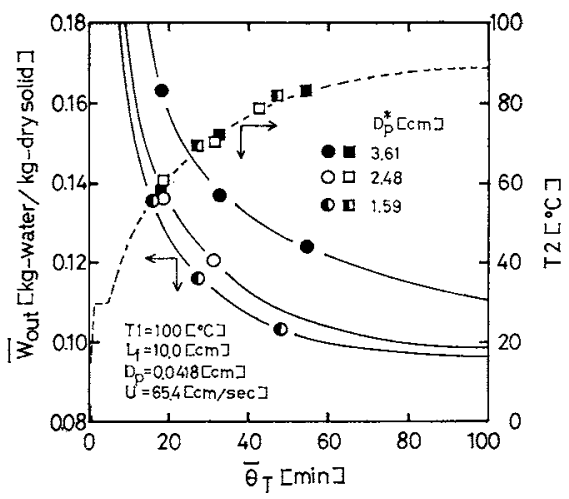

Fig. 7 Effect of $D_{p}^{*}$ upon $\bar{w}_{\text {out }}, T 2$

when the superficial gas velocity is large, the moisture content of outlet particles becomes small and the outlet gas temperature becomes high at constant average residence time of particles in the bed.

Figure 6 shows the relationship between moisture content of outlet particles, outlet gas temperature and average residence time of particles in the bed, with bed height as a parameter. When the bed height is low, the moisture content of outlet particles becomes small and the outlet gas temperature becomes high at constant average residence time of particles in the bed.

Figure 7 shows the relationship between moisture content of outlet particles, outlet gas temperature and average residence time of particles in the bed, with packing size as a parameter. When the packing size is small, the moisture content of outlet particles becomes small at constant average residence time of particles in the bed, while the outlet gas temperature is not strongly affected by packing size. The particle flow pattern in the bed may be strongly affected by packing size.

\section{3 Comparison of experimental and calculated results}

Figure 8 shows the effect of superficial gas velocity on the drying characteristics in the continuous packed fluidized bed. From this figure, when the superficial gas velocity is large, the drying rates become fast. The moisture content of outlet particles in the case of the plug flow model is smaller than that in the case of

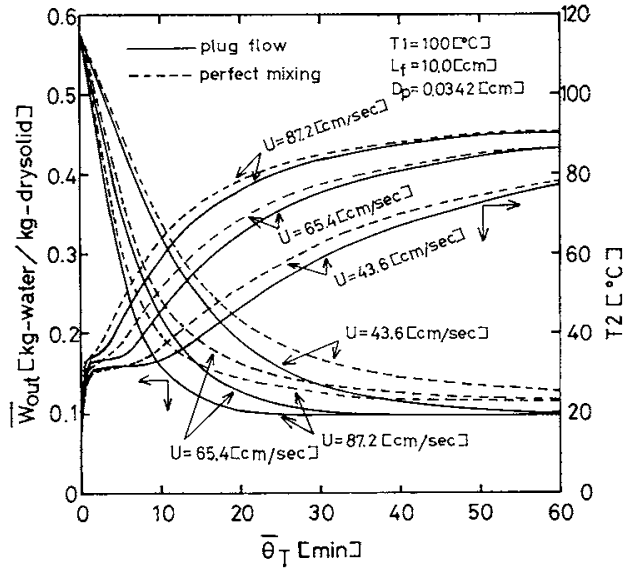

Fig. 8 Effect of superficial gas velocity upon drying characteristics

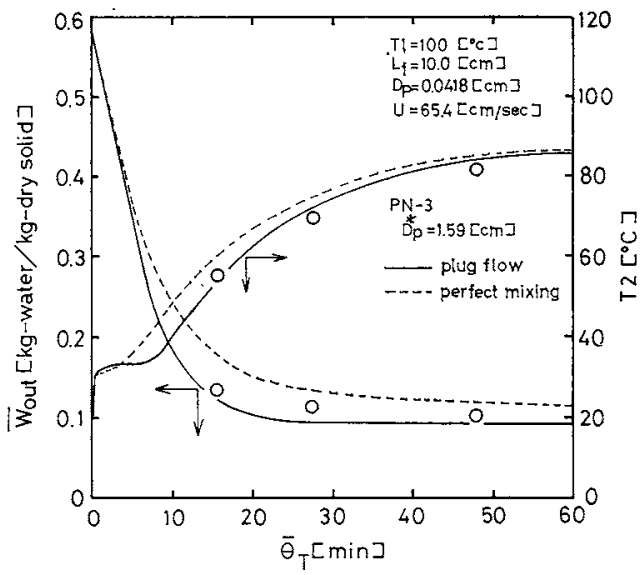

Fig. 9 Relationship between $\bar{w}_{\text {out }}, T 2$ and $\bar{\theta}_{T}$

the perfect mixing model at the same average residence time of particles. This fact means that fluidized particles are dried effectively when the particle flow pattern is plug flow.

Figure 9 compares the calculated moisture content of outlet particles and outlet gas temperature with the experimental values. From Fig. 9, when the packing size is small, the experimental values agree well with the calculated ones based upon the plug flow model for particle flow pattern in the bed.

Figure 10 compares calculated and experimental values of moisture content of outlet particles in the case of the plug flow model for the particle flow pattern in the bed. From Fig. 10, when the packing size is small and the bed height is low, the calculated values agree approximately with the experimental ones. However, when the packing size is large and the bed height is high, the calculated values do not agree with the experimental ones.

\section{Discussion}

In the batch operation, when the moisture content of particles in the bed reached the equilibrium moisture 


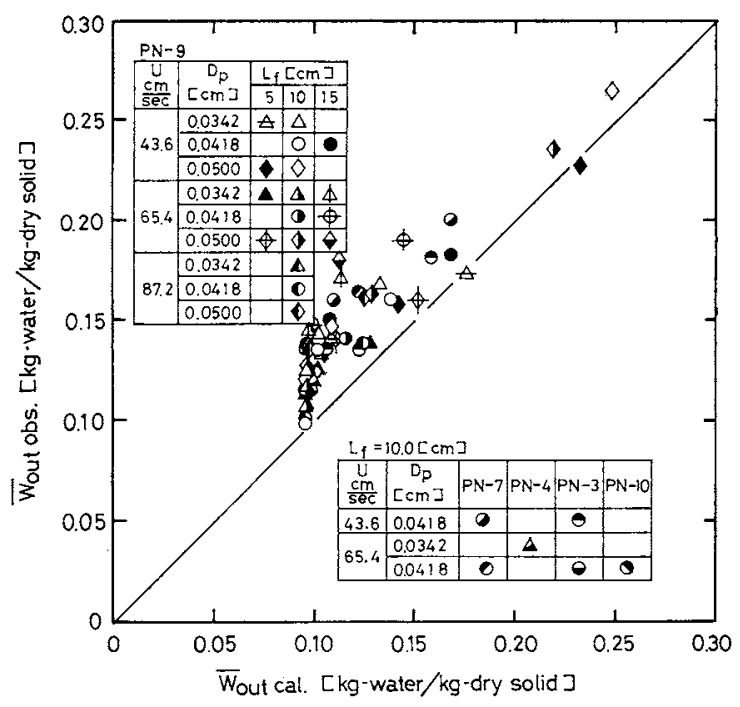

Fig. 10 Comparison of calculated mean moisture content of outlet particles with observed values

content, outlet gas temperature became lower than inlet gas temperature because of the heat loss from the bed wall. Therefore, in the analysis of the drying characteristics of the packed fluidized bed dryer, heat loss from the bed wall was considered. From the experimental estimation of heat transfer rate to the bed wall, the overall heat transfer coefficient at the bed wall was about $3.5 \mathrm{kcal} / \mathrm{m}^{2} \cdot \mathrm{hr} \cdot{ }^{\circ} \mathrm{C}$.

To investigate the effect of particles mixing in the bed upon the drying characteristics in the packed fluidized bed, the drying characteristics was analyzed by the plug flow model or the perfect mixing model for the particle flow pattern in the bed. Figures 9 and 10 show that when the packing size is small, the experimental values agree approximately with the calculated ones based upon the plug flow model for the particle flow pattern in the bed. When the packing size is large, the experimental values agree approximately with the calculated ones based upon the perfect mixing model. The lateral particle flow pattern in the bed is affected by the lateral particle mixing coefficient, the lateral particle flow rate and the lateral length of the bed. If the packing size is smaller than $2.5 \mathrm{~cm}$ and the average residence time of particle in the bed is less than 30 minutes, the drying characteristics in the bed can be satisfactorily analyzed by the plug flow model for the particle flow pattern in the bed.

\section{Conclusion}

1) The drying rate in the constant drying rate period can be estimated by the empirical equation for gas-particle heat transfer coefficient obtained by Kato et $a l .{ }^{1}$, and the drying rate in the falling drying rate period is proportional to the free moisture content in the particles.

2) The drying rate in a packed fluidized bed dryer is affected by superficial gas velocity, bed height, temperature of inlet gas and packing size.

3) The drying characteristics of a continuous packed fluidized bed dryer can be analyzed by the plug flow model for the gas flow pattern and the plug flow model or the perfect mixing model for the particle flow pattern in the bed.

\begin{tabular}{|c|c|c|}
\hline \multicolumn{3}{|c|}{ Nomenclature } \\
\hline$A$ & $=$ cross-sectional area of bed & {$\left[\mathrm{cm}^{2}\right]$} \\
\hline$A_{l}$ & $=$ total area of side wall & {$\left[\mathrm{cm}^{2}\right]$} \\
\hline$a$ & $\begin{aligned}= & \text { specific surface of particles } \\
& \text { volume of bed }\end{aligned}$ & per unit \\
\hline$C_{H}$ & $=$ humid heat & {$\left[\mathrm{kcal} / \mathrm{kg}\right.$-dry gas $\left.\cdot{ }^{\circ} \mathrm{C}\right]$} \\
\hline$C_{p g}$ & $=$ specific heat of gas & {$\left[\mathrm{kcal} / \mathrm{kg} \cdot{ }^{\circ} \mathrm{C}\right]$} \\
\hline$C_{p s}$ & $=$ specific heat of particle & {$\left[\mathrm{kcal} / \mathrm{kg} \cdot{ }^{\circ} \mathrm{C}\right]$} \\
\hline$C_{p w}$ & $=$ specific heat of water & {$\left[\mathrm{kcal} / \mathrm{kg} \cdot{ }^{\circ} \mathrm{C}\right]$} \\
\hline$C_{w}$ & $=$ specific heat of vapor & {$\left[\mathrm{kcal} / \mathrm{kg} \cdot{ }^{\circ} \mathrm{C}\right]$} \\
\hline$D_{p}$ & $=$ particle diameter & {$[\mathrm{cm}]$} \\
\hline$D_{p}{ }^{*}$ & $\begin{aligned}= & \text { equivalent diameter of pac } \\
& \text { as }\left(3 / 2 d^{2} h_{c}\right)^{1 / 3}\end{aligned}$ & king defined \\
\hline$d$ & $=$ diameter of screen packing & [cm] \\
\hline$G$ & $=$ total mass flow rate of gas & {$[\mathrm{kg} / \mathrm{hr}]$} \\
\hline$H_{1}$ & $=$ humidity of inlet gas & [kg-water/kg-dry gas] \\
\hline $\mathrm{H}_{2}$ & $=$ humidity of outlet gas & [kg-water $/ \mathrm{kg}$-dry gas] \\
\hline$h$ & $=$ gas-particle heat transfer $\mathrm{c}$ & oefficient \\
\hline
\end{tabular}

$\left[\mathrm{kcal} / \mathrm{m}^{2} \cdot \mathrm{hr} \cdot{ }^{\circ} \mathrm{C}\right]$

ha $=$ heat capacity coefficient $\quad\left[\mathrm{kcal} / \mathrm{m}^{3} \cdot \mathrm{hr} \cdot{ }^{\circ} \mathrm{C}\right]$

$h_{c} \quad=$ length of screen packing $\quad[\mathrm{cm}]$

$h_{l} \quad=$ the overall heat transfer coefficient at the bed wall $\quad\left[\mathrm{kcal} / \mathrm{m}^{2} \cdot \mathrm{hr} \cdot{ }^{\circ} \mathrm{C}\right]$

$J^{\prime}(\theta) \quad=$ residence time distribution function $\quad\left[\mathrm{sec}^{-1}\right]$

$K_{g} \quad=$ thermal conductivity of gas $\quad\left[\mathrm{kcal} / \mathrm{m} \cdot \mathrm{hr} \cdot{ }^{\circ} \mathrm{C}\right]$

$L=$ peripheral length of bed $[\mathrm{cm}]$

$\begin{array}{lll}L_{f} & =\text { expanded bed height }\end{array}$

$L_{H} \quad=$ bed width [cm]

$\begin{array}{ll}L_{m f}= & \text { bed height at minimum fluidizing } \\ \text { conditions } & \text { [cm] }\end{array}$

$\mathrm{Nu} \quad=\begin{aligned} & \text { Nusselt number for gas-particle } \\ & \text { heat transfer }\end{aligned}$

$R \quad=$ drying rate $\quad\left[\mathrm{kg} / \mathrm{m}^{2} \cdot \mathrm{hr}\right]$

$R c w \quad=$ drying rate in constant drying rate period

[kg-water $/ \mathrm{kg}$-dry solid $\cdot \mathrm{hr}]$

$R d w \quad=$ drying rate in falling drying rate period

[kg-water/kg-dry solid $\cdot \mathrm{hr}]$

Rep = particle Reynolds number [-]

$r_{m} \quad=$ latent heat of vaporization $\quad[\mathrm{kcal} / \mathrm{kg}$ ]

$r_{w} \quad=$ latent heat of vaporization at wet-bulb temperature

$S_{p} \quad=$ surface of a particle $\quad\left[\mathrm{cm}^{2}\right]$

$[\mathrm{kcal} / \mathrm{kg}$ ]

$\begin{array}{lll}T & =\text { temperature of gas } & {\left[{ }^{\circ} \mathrm{C}\right]}\end{array}$

$\begin{array}{lll}T_{1} & =\text { temperature of inlet gas } & {\left[{ }^{\circ} \mathrm{C}\right]}\end{array}$

$\begin{array}{lll}T_{2} & =\text { temperature of outlet gas } & {\left[{ }^{\circ} \mathrm{C}\right]}\end{array}$

$T_{g} \quad=$ mean temperature of gas in the bed $\quad\left[{ }^{\circ} \mathrm{C}\right]$

$t_{F^{\prime}} \quad=$ temperature of feed particles (room temperature)

$\begin{array}{lll}t_{m} & =\text { temperature of particle } & {\left[{ }^{\circ} \mathrm{C}\right]}\end{array}$

$\begin{array}{lll}t_{w} & =\text { wet-bulb temperature } & {\left[{ }^{\circ} \mathrm{C}\right]}\end{array}$

$\begin{array}{lll}\bar{t}_{m 2} & =\text { mean temperature of outlet particles } \quad\left[{ }^{\circ} \mathrm{C}\right]\end{array}$

$\begin{array}{lll}U & =\text { superficial gas velocity } \quad[\mathrm{cm} / \mathrm{sec}]\end{array}$

$U_{s} \quad=$ particle velocity to lateral direction $\quad[\mathrm{cm} / \mathrm{sec}]$

$U_{m f} \quad=$ minimum fluidized gas velocity $\quad[\mathrm{cm} / \mathrm{sec}]$

$V \quad=$ volume of bed $\quad\left[\mathrm{cm}^{3}\right]$ 


\begin{tabular}{|c|c|c|}
\hline$V_{p}$ & $=$ volume of particle & {$\left[\mathrm{cm}^{3}\right]$} \\
\hline$W$ & $=$ feed rate of particles & $\mathrm{kg} / \mathrm{hr}]$ \\
\hline$W_{p}$ & $=$ weight of particle & [g] \\
\hline$w$ & $=$ moisture content of particle & \\
\hline & & [kg-water/kg-dry solid] \\
\hline$w_{c}$ & $\begin{array}{l}=\text { critical moisture content } \\
\qquad[\mathrm{kg} \text {-water } / \mathrm{kg} \text { - } \mathrm{dry}\end{array}$ & [kg-water/kg-dry solid] \\
\hline$w_{e}$ & $\begin{array}{l}=\text { equilibrium moisture content } \\
\qquad[\mathrm{kg} \text {-water } / \mathrm{kg} \text {-dry }\end{array}$ & solid] \\
\hline$w_{F}$ & $\begin{array}{l}=\text { moisture content of feed particles } \\
\qquad[\mathrm{kg} \text {-water } / \mathrm{kg} \text {-dry }\end{array}$ & solidl \\
\hline $\bar{w}_{\text {out }}$ & $\begin{array}{l}=\text { mean moisture content of outlet particles } \\
\qquad[\mathrm{kg} \text {-water } / \mathrm{kg} \text {-dry }\end{array}$ & solid] \\
\hline$X_{T}$ & $=$ lateral length of bed & [cm] \\
\hline$x$ & $=$ lateral distance from particle feed point & [cm] \\
\hline$x_{p}$ & $=$ lateral length of bed for preheating period & [cm] \\
\hline$x_{c}$ & $\begin{array}{l}=\text { lateral length of bed for preheating } \\
\text { and constant drying rate periods }\end{array}$ & [cm] \\
\hline$Z$ & $=$ axial length & {$[\mathrm{cm}]$} \\
\hline$\varepsilon_{b}$ & $=$ void fraction of packing & {$[-]$} \\
\hline$\varepsilon_{m f}$ & $\begin{array}{l}=\text { void fraction under minimum fluidizing } \\
\text { conditions }\end{array}$ & {$[-]$} \\
\hline
\end{tabular}

\section{Literature Cited}

1) Kato, K., H. Ito and S. Omura: J. Chem. Eng. Japan, 12, 403 (1979).

2) Mrowiec, M. and W. Ciesielczyk: Int. Chem. Eng., 17, 373 (1977).

3) Toei, R. and R. Matsuno: Kagaku Kögaku, 29, 949 (1965).

4) Toei, R., S. Hayashi, T. Naito, M. Okazaki and M. Agata: ibid., 23, 641 (1959).

5) Toei, R.: Kagaku Kikai Gijutsu, 15, 22 (1963).

void fraction under minimum fluidizing 